\title{
Gilles De Rome, Théorèmes sur l'être et l'essence Introduction, traduction et notes de Stéphane
} Mercier.

Paris, Les Belles Lettres, coll. « Sagesses médiévales », 2011, 266 p.

\section{Mustapha Naïmi}

\section{CpenEdition}

Journals

Édition électronique

URL : http://journals.openedition.org/assr/24298

DOI : $10.4000 /$ assr.24298

ISSN : $1777-5825$

Éditeur

Éditions de l'EHESS

Édition imprimée

Date de publication : 30 décembre 2012

Pagination : 157

ISSN : 0335-5985

Référence électronique

Mustapha Naïmi, « Gilles De Rome, Théorèmes sur l'être et l'essence Introduction, traduction et notes de Stéphane Mercier. », Archives de sciences sociales des religions [En ligne], 160 | octobre-décembre 2012, mis en ligne le 22 février 2013, consulté le 21 septembre 2020. URL : http:// journals.openedition.org/assr/24298; DOI : https://doi.org/10.4000/assr.24298

Ce document a été généré automatiquement le 21 septembre 2020.

(C) Archives de sciences sociales des religions 
Gilles De Rome, Théorèmes sur l'être et l'essence Introduction, traduction et notes de Stéphane Mercier.

Paris, Les Belles Lettres, coll. « Sagesses médiévales », 2011, 266 p.

Mustapha Naïmi

\section{RÉFÉRENCE}

Gilles De Rome, Théorèmes sur l'être et l'essence, Introduction, traduction et notes de Stéphane Mercier. Paris, Les Belles Lettres, coll. « Sagesses médiévales », 2011, 266 p. 
1 En 1930, Hocedez publie une première édition critique des Theoremata de esse et essentia, en la dotant d'une introduction substantielle où il établit le rôle majeur de Gilles de Rome dans la controverse sur la distinction réelle d'être et d'essence. En 1952, M. Murray publie une première traduction de ce traité en langue anglaise. Plus de quatre-vingts ans sans qu'aucune traduction française n'ait encore vu le jour. C'est pour remédier à cet état des choses que Stéphane Mercier propose, pour la première fois en français, une traduction intégrale de l'ensemble des vingt-deux théorèmes qui composent le traité de Gilles de Rome né entre 1243 et 1247. Il la fait précéder d'une introduction en trois chapitres. Le premier présente brièvement les étapes importantes de la vie de Gilles de Rome, qui permettent de mieux comprendre les circonstances et les enjeux de ses différents écrits. Ensuite, il tâche de situer les Theoremata dans le contexte plus large de la controverse qui, entre 1276 et 1287, opposa Gilles de Rome à Henri de Gand à propos de la distinction réelle. Enfin, il propose une lecture de la doctrine égidienne de l'être comme res; pour cela il s'efforce de dégager le véritable propos de l'auteur en s'attachant à distinguer, autant que possible, ce qu'il y a de juste et de moins juste dans les diverses interprétations auxquelles sa manière de dire l'être a donné lieu.

2 Le 18 janvier 1277 marque un tournant important dans la vie de Gilles de Rome, comme dans la vie intellectuelle du Moyen Âge en général. Le pape Jean XXI demande à l'évêque de Paris de mener une enquête sur les erreurs circulant à l'Université, les fauteurs des erreurs et les lieux où ils étaient professés. Emporté par son zèle, le prélat outrepasse manifestement la demande papale et transforme l'enquête en un procès qui aboutit, le 7 mars, à la condamnation d'une série de deux cent dix-neuf propositions « averroïstes ». Le catalogue des erreurs visait un ensemble de thèses enseignées à la faculté des Arts. Thomas d'Aquin fut touché indirectement comme Gilles de Rome. Un procès sera bientôt réservé à de Rome ayant pour argument le fait qu'il ressuscite le spectre d'une alliance entre la théologie et l'audacieux paganisme de certains maîtres de la faculté des arts. On lui lance une menace d'excommunication après le 7 mars. La procédure de Tempier, l'évêque de Paris, intéresse moins l'auteur que la condamnation de l'unicité de la forme substantielle. Il avait soutenu cette thèse dans ses TCC où il présentait la thèse de l'unicité comme "extrêmement probable " sans pourtant se risquer à une affirmation catégorique. Devant la commission convoquée par Tempier en vue d'examiner un ensemble de cinquante et un articles, Gilles de Rome refuse de rétracter les thèses formulées dans ce syllabus et rédige son Apologie, compromettant son accès à la maîtrise. N'ayant plus rien à faire à Paris, il demeure entre 1281 et 1285 en Italie où, sans doute, il remplit diverses charges importantes au sein de son ordre. Il 
était alors encore le seul bachelier en titre de l'Université de Paris. Régulièrement présent aux différents chapitres provinciaux tenus à cette époque, Gilles y occupe une place importante et se vit, entre autres choses, attribuer la faculté de désigner le prieur provincial de Rome. C'est de cette époque également que datent les Theoremata de esse et essentia (TEE) sans qu'il soit possible de situer précisément la date de leur composition.

Thomas d'Aquin et Averroès avaient constamment rejeté la distinction réelle de l'essence et de l'existence qu'admettait Avicenne. Cette manière de comprendre la distinction réelle ne se trouve pas chez Gilles de Rome qui parlait de séparabilité, ce qui ne signifie pas qu'il concevait la distinction sur un mode proprement physique. Il était d'abord marqué par le néoplatonisme, mais surtout avicennien au sens où l'être tel qu'il le concevait pouvait être considéré comme un pur accident de l'essence. Par conséquent, son accord avec Thomas d'Aquin n'eût jamais été que verbal, puisque ce dernier rejetait nettement la distinction telle que le concevait l'Avicenne d'Averroès.

4 La métaphysique de De Rome, à cet égard, ne fait pas figure d'exception: en contribuant au grand dialogue scolastique, elle est un partenaire de plus dans une quête jamais achevée, puisqu'elle vise le vrai de l'être et par là le vrai tout entier, dans son immensité irréductible à tout discours philosophique. Une quête sans fin mais qui, pour autant, n'est pas vaine. 